\title{
Assessment of cellular actin dynamics by measurement of fluorescence anisotropy
}

\author{
Jean-Alexis Spitz ${ }^{\mathrm{a}, \mathrm{b}, *, 1}$, Valérie Polard ${ }^{\mathrm{a}, \mathrm{c}, 1}$, Andréi Maksimenko ${ }^{\mathrm{a}, \mathrm{c}}$, Frédéric Subra ${ }^{\mathrm{a}}$, \\ Catherine Baratti-Elbaz ${ }^{\text {a }}$, Rachel Méallet-Renault ${ }^{\mathrm{b}}$, Robert B. Pansu ${ }^{\mathrm{b}}$, \\ Patrick Tauc ${ }^{\text {a }}$, Christian Auclair ${ }^{\mathrm{a}, *}$ \\ a LBPA, Institut d'Alembert, ENS Cachan, CNRS, UniverSud, 61 av President Wilson, F-94230 Cachan, France \\ b PPSM, Institut d'Alembert, ENS Cachan, CNRS, UniverSud, 61 av President Wilson, F-94230 Cachan, France \\ ${ }^{\mathrm{c}}$ BioAlliance Pharma, 59 boulevard du Général Martial Valin, F-75015 Paris, France
}

Received 5 February 2007

Available online 5 April 2007

\begin{abstract}
To study cellular actin dynamics, a cell-free assay based on fluorescence anisotropy was developed. Using G-actin-Alexa as a probe, we found that anisotropy enhancement reflects F-actin elongation. Anisotropy enhancement varies with the concentration of magnesium and calcium cations and with ethylenediaminetetraacetate or well-known effectors of the polymerization. This assay gives the overall status of actin dynamics in cell extracts which are the closest conditions to in vivo, implying most of the regulating proteins that are missing in purified actin measurements. It can be used in a large-scale screening for chemical compounds which modulate actin polymerization. (C) 2007 Elsevier Inc. All rights reserved.
\end{abstract}

Keywords: Actin cytoskeleton; Fluorescence anisotropy; Polymerization

In eukaryotic cells, the actin network is essential for several important processes such as cell motility, cell adhesion, phagocytosis, exocytosis, and endocytosis [1]. The actin cytoskeleton plays critical roles in cell division [2-4], adhesion [5,6], contact inhibition and apoptosis [7], and malignant transformation [5,8]. Disruption of actin filaments and decrease in focal adhesions are common features of transformed cells. Actin remodeling, by shifting G-actin/ F-actin ratio, is regulated by actin signaling proteins, the most important being the ras-related superfamily of small GTPases [9-12].

It is of major interest to develop tools allowing (i) assessment of actin dynamic status in cells and (ii) identification of compounds which may act as actin dynamics

\footnotetext{
* Corresponding authors. Fax: +330147407671.

E-mail address: auclair@lbpa.ens-cachan.fr (C. Auclair).

${ }^{1}$ These authors contributed equally to this work.
}

modulators either through a direct interaction with actin or through an indirect interaction with regulatory proteins.

The pyrenyl fluorescence assay [13] is a convenient, nondestructive method which is extensively used for actin dynamics measurement. Although highly suitable using purified actin, this method appears to be less adapted for measuring cellular actin dynamics in cell-free system for various reasons including photobleaching, fluorescence quenching, and protein autofluorescence.

Alternative techniques using polystyrene beads coated with nucleating proteins which can be used either in purified actin or in cytosolic extracts and which allows the study of actin-driven movements and actin polymerization dynamics have been proposed [14].

In this study, we propose a new actin polymerization assay based on the measurement of static fluorescence anisotropy of an actin-Alexa conjugate. 


\section{Materials and methods}

\section{Reagents}

AlexaFluor488 carboxylic acid succinimidyl ester (A20000), AlexaFluor488-phalloidin (A12379), and AlexaFluor488-actin (A12373) were purchased from Molecular Probes (Eugene, OR, USA). Poly-(L)-lysine and spectrophotometric-grade solvents were from Sigma-Aldrich (Saint Louis, MO, USA). Purified rabbit muscle actin (AKL99-A) was purchased from Cytoskeleton (Denver, CO, USA).

\section{Apparatus}

UV-visible spectra were recorded on a Varian Cary (Palo Alto, CA, USA) double-beam spectrometer using a 10-mm-path quartz cell from Thuet (Bodelsheim, France). Fluorescent spectra (emission and excitation) were recorded on a Jobin Yvon (Edison, NJ, USA) Fluorolog3 fluorimeter. The static fluorescence anisotropy signal was obtained with a PanVera Beacon 2000 (Madison, WI, USA), using 490-nm excitation and 520-nm emission wavelengths. The fluorescence decay curves were obtained with a time-correlated single-photon-counting method using a titanium-sapphire laser $(82 \mathrm{MHz}$, repetition rate lowered to $4 \mathrm{MHz}$ using a pulse-peaker, 1 ps pulse width, doubling crystal to reach $495 \mathrm{~nm}$ excitation) pumped by an argon ion laser from Spectra Physics (Mountain View, CA, USA). Confocal microscopy imaging was carried out on a laser scanning spectral confocal microscope TCS SP2 from Leica Microsystems (Wetzlar, Germany).

\section{Cell culture}

The NIH 3 T3 murine fibroblast cell line was purchased from ATCC (CRL1658). The EWS-Fli1-transformed NIH 3T3 cell line (NIH 3T3 EF) was a gift from Dr J. Ghysdael (Orsay, France). These cells are NIH 3T3 fibroblasts that have been stably transduced by the cDNA encoding the type 1 EWS-Flil fusion protein inserted downstream of the Mo-MuLV long terminal repeat in the pBabe-puro retroviral vector. These cell lines were grown in Dulbecco's modified Eagles'medium supplemented with 10\% heatinactivated newborn calf serum, $100 \mathrm{UI} / \mathrm{mL}$ penicillin, and $100 \mu \mathrm{g} / \mathrm{mL}$ streptomycin (all from Gibco BRL) at $37{ }^{\circ} \mathrm{C}$ in a humidified $5 \% \mathrm{CO}_{2}$ atmosphere. NIH $3 \mathrm{~T} 3 \mathrm{EF}$ cells were selected with $2.5 \mu \mathrm{g} / \mathrm{mL}$ puromycin (Sigma).

\section{Preparation of cell extracts}

Cells were trypsinized and washed two times at room temperature with $\mathrm{pH} 6.5$ washing buffer $(135 \mathrm{mM} \mathrm{NaCl}$, $2.7 \mathrm{mM} \mathrm{KCl}, 11.9 \mathrm{mM} \mathrm{NaHCO} 3,0.36 \mathrm{mM} \mathrm{NaH} \mathrm{PO}_{4}$, $2 \mathrm{mM} \mathrm{MgCl}, 0.2 \mathrm{mM}$ EGTA, $5.5 \mathrm{mM}$ glucose, and $0.3 \%$ bovine serum albumin) [15]. Cells $\left(5.10^{7}\right)$ were resuspended in sonication buffer $(10 \mathrm{mM}$ Tris- $\mathrm{HCl}, \mathrm{pH} 7.5$,
$10 \mathrm{mM}$ EGTA, $2 \mathrm{mM} \mathrm{MgCl}_{2}$ ) [15] containing a complete protease inhibitors mixture (Roche). Cells were lysed on ice by minimal sonication required to break the cells (Vibracell Novodirect) and centrifuged at $6900 \mathrm{~g}$ for 30 $\min$ at $4{ }^{\circ} \mathrm{C}$. The cleared supernatant was carefully removed and passed through a $0.45-\mu \mathrm{m}$ filter. The protein concentration was determined using the Bradford method (Bio-Rad). The supernatant was supplemented with 150 $\mathrm{mM}$ sucrose, $0.2 \mathrm{mM}$ ATP, and $0.2 \mathrm{mM} \mathrm{DTT}^{2}$ added per mg. $\mathrm{mL}^{-1}$ of total proteins. The cellular extracts were aliquoted, frozen in liquid nitrogen, and then stored at -80 ${ }^{\circ} \mathrm{C}$. Extracts can be frozen at $-80^{\circ} \mathrm{C}$ without loss of activity and storing on ice allowed assays to extend over $4-5 \mathrm{~h}$ without alterations in anisotropy measurements.

\section{Actin-Alexa488-mediated steady state fluorescence anisotropy measurement assays}

All reactions were carried out at $22{ }^{\circ} \mathrm{C}$ and the fluorescence anisotropy signal was detected at $520 \mathrm{~nm}$ with excitation at $490 \mathrm{~nm}$ in a Beacon 2000. Actin-Alexa488 was ultracentrifuged at $150,000 \mathrm{~g}$ for $2 \mathrm{~h}$ at $4{ }^{\circ} \mathrm{C}$ to sediment residual actin polymers. The fluorescence remaining in the supernatant was considered to be most likely due to monomers or small actin filaments (5-10 monomers) that do not pellet under conditions described previously [16]; $80 \%$ of the supernatant was recovered, and the concentration was defined using fluorescence measurements (excitation at $490 \mathrm{~nm}$ and signal recovery at $520 \mathrm{~nm}$ ). The ultracentrifuged actin concentration was calculated using the noncentrifuged actin-Alexa488 as a standard. The supernatant was aliquoted, frozen in liquid nitrogen, and stored at $-80{ }^{\circ} \mathrm{C}$. Before experiment, an aliquot of ultracentrifuged actin-Alexa488 was diluted to a concentration of $1 \mathrm{mg} / \mathrm{mL}$ in $\mathrm{G}$ buffer $\left(5 \mathrm{mM}\right.$ Tris, $\mathrm{pH} 8.1,2 \mathrm{mM} \mathrm{CaCl}_{2}$, $0.2 \mathrm{mM}$ DTT, and $0.2 \mathrm{mM} \mathrm{ATP})$. Actin-Alexa is used as a tracer ( $5 \%$ of final protein concentration). Then $3 \mu \mathrm{L}$ of diluted actin-Alexa488 (final concentration $0.01 \mathrm{mg} / \mathrm{mL}$ ) was mixed in $167 \mu \mathrm{L}$ G buffer and actin monomers anisotropy was measured before the addition of $4 \mu \mathrm{L}$ of polymerization buffer ( $2.5 \mathrm{M} \mathrm{KCl}, 50 \mathrm{mM} \mathrm{MgCl} 2,25 \mathrm{mM} \mathrm{ATP})$ and $20 \mu \mathrm{L}$ of cellular extract with a concentration of $2 \mathrm{mg} \cdot \mathrm{mL}^{-1}$ of total protein. Measurements were made every $10 \mathrm{~s}$ for a 200 -s period. The anisotropy enhancement (arbitrary units; AU) is the difference between the final state and the initial measured anisotropy multiplied by 1000. The data were fitted based upon a pseudo-first-order model with the equation $\Delta \mathrm{AU}=\Delta \mathrm{AU}_{\max }[1-\exp (-k . t)]$, where $t$ is the time variable, $\Delta \mathrm{AU}_{\max }$ corresponds to the steady state anisotropy value, and $k$ is the rate constant of actin elongation. For the studies of depletion in calcium or magnesium ions, other buffers were prepared. To eliminate exogenous sources of magnesium ions, the sonication buffer and the polymerization buffer were prepared without

\footnotetext{
${ }^{2}$ Abbreviation used: DTT, dithiothreitol
} 
$\mathrm{MgCl}_{2}$. To eliminate calcium ions in the experiments, $\mathrm{G}$ buffer was prepared without $\mathrm{CaCl}_{2}$.

\section{In vitro microfilament imaging}

Purified $\mathrm{G}$ actin $\left(0.2 \mathrm{mg} \cdot \mathrm{mL}^{-1}\right)$ was allowed to polymerize for $15 \mathrm{~min}$ at $37{ }^{\circ} \mathrm{C}$ in a polymerizing buffer $(\mathrm{KCl}$, $\mathrm{MgCl}_{2}$, ATP). Phalloidin-AlexaFluor488 was added at $0.15 \mu \mathrm{M}$ final concentration and allowed to bind to F-actin for $20 \mathrm{~min}$ at $37^{\circ} \mathrm{C}$. Samples were then dropped carefully onto a poly-(L)-lysine-coated glass slide and incubated for a further $60 \mathrm{~min}$ at $37{ }^{\circ} \mathrm{C}$ to allow adsorption on the poly-(L)-lysine-coated surface. The slide was then mounted with a cover slip and examined by confocal microscopy.

\section{Results}

\section{Fluorescence properties of Alexa488}

Alexa488 is a rhodamine derivative which displays a high fluorescence quantum yield of 0.96 in water and a remarkable resistance to photobleaching. The spectroscopy of this dye shows as expected a narrow absorption band centered on $493 \mathrm{~nm}$ in water and a maximum fluorescence emission at $518 \mathrm{~nm}$. The study of Alexa488 in different solvents with various viscosities shows that it could be used as a motion probe because of its anisotropy changes. Indeed stationary anisotropy increases with viscosity as shown in Table 1. Moreover, the time-resolved characteristic constants $\left(\tau_{\mathrm{C}}\right)$ increases also. Below a relative viscosity of 15 , $\tau_{\mathrm{C}}$ is correlated with viscosity $\left(R^{2}=0.9985\right)$. It is worth noticing that the fluorescence lifetime and quantum yield are not affected by such a viscosity change.

The time-resolved anisotropy function, $r(t)$, was calculated (without deconvoluting the instrument response function) from the Perrin equation $[17,18], r(t)=\frac{\mathrm{Ivh}-G * \mathrm{Ihh}}{\mathrm{Ivh}+2 * G * \mathrm{Ihh}}$, where $G=\frac{\mathrm{Ivv}}{\mathrm{IVh}}$ is the apparatus function and $\mathrm{I}_{x y}$ are the four geometric components of the fluorescence polarization with the first index standing for excitation and the second for emission ( $\mathrm{v}=$ vertical, $\mathrm{h}=$ horizontal). This anisotropy decay is then fitted by a monoexponential function whose characteristic time is the rotational diffusion time $\left(\tau_{\mathrm{C}}\right)$.

\section{Fluorescence anisotropy of actin-Alexa488 complexes}

Using experimental conditions and data treatment similar to those described above, we measured the fluorescence anisotropy parameters of G-actin-Alexa488 first dissolved in aqueous medium and second in the presence of increasing concentration of glycerol. In aqueous medium ( $\mathrm{G}$ buffer), Alexa488 covalently bound to G-actin displays a rotational diffusion time of $0.36 \mathrm{~ns}$ (Fig. 1) which is a slightly higher value than that observed with free Alexa488 $(0.17 \mathrm{~ns})$. This rather low rotational diffusion time value is consistent with a rapid rotational motion of Alexa488 due to the flexibility of the chain which links Alexa488 to actin. Such a short diffusion time cannot be attributed to the global protein rotation which can be evaluated to $16 \mathrm{~ns}$. Nevertheless, when a biexponential fit is applied with such a long component, the contribution of the long component (rotation) is less than $3 \%$ of the global decay while the short component (flexibility of the chromophore) is not modified. We performed further time-resolved spectroscopy measurements of actin-Alexa488 dissolved in $\mathrm{G}$ buffer containing 5, 25, or 50\% glycerol (Fig. 1). Once more, we note that the decays are monoexponential and that the fluorescence lifetime and quantum yield are not modified upon viscosity change.

As expected, the rotational diffusion index increases with glycerol concentration which reflects the decrease of the rotational motion due to increased viscosity of the medium. We finally promote G-actin polymerization in a medium containing 5\% G-actin-Alexa488/95\% unlabeled G-actin. Under these conditions, actin-Alexa488 is a tracer and as reported by Bear et al. [19] the chromophore does not interfere in the formation of F-actin. Stationary anisotropy value increased upon actin polymerization up to 165 AU whereas the average characteristic time of the anisotropy decay shows an evolution similar to that of actin polymerization up to a value of $2.30 \mathrm{~ns}$ (Supplementary Fig. 1). Such a value is in the same range as that of Alexa in $50 \%$ glycerol. The increases in the fluorescence anisotropy signal and rotational diffusion index clearly show that, when inserted in an actin filament, actin-Alexa488 is subjected to more limited motion than is the monomeric actinAlexa488 form. The extent of increase of the anisotropy signal was assessed to be sufficient for measuring actin dynamics parameters under various conditions.

\section{Fluorescence anisotropy enhancement reflects actin dynamics in NIH-3T3 fibroblast cytosolic fractions}

Using the standard operating conditions as described under Materials and methods, we have measured the

Table 1

Variations of anisotropy of Alexa488 in different solvents with various viscosities

\begin{tabular}{lllllcc}
\hline Solvent & Water & Glycerol $10 \%$ & Glycerol $30 \%$ & Glycerol $50 \%$ & Cyclohexanol & Glycerol $70 \%$ \\
\hline$\eta / \eta_{0}$ & 1.0 & 1.3 & 3.2 & 15.4 & 41 & 480 \\
Stationary anisotropy & 0.018 & 0.020 & 0.054 & 0.164 & 0.201 & 0.308 \\
$\tau_{\mathrm{c}}(\mathrm{ns})$ & 0.17 & 0.24 & 0.70 & 2.07 & 4.70 & 7.70 \\
\hline
\end{tabular}

Stationary anisotropy and characteristic time of the anisotropy decay of Alexa488 (1.55 $\mu \mathrm{M})$ were determined in water, cyclohexanol, and a mix of $10 \%$ glycerol and water (respectively, 30,50 and $70 \%$ ). $\eta$ represents viscosity of the considered solvent, $\eta_{0}$ is viscosity of water, and $\tau_{\mathrm{C}}$ is the rotational diffusion time. 


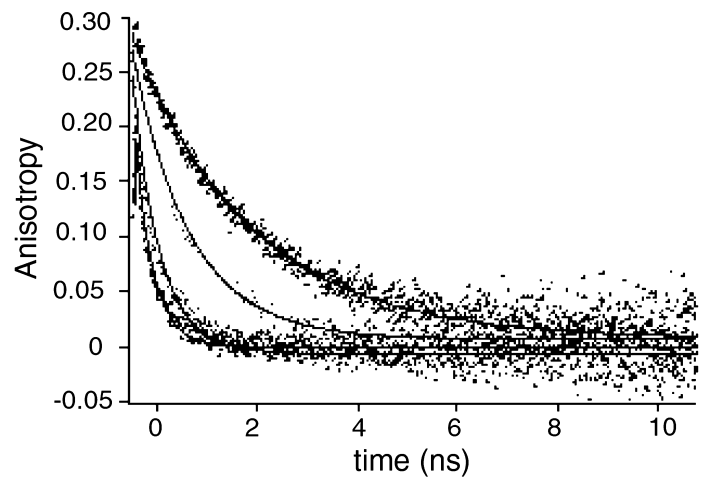

Fig. 1. Effect of viscosity on time-resolved anisotropy of G-actin-Alexa. Characteristic time of the anisotropy decay of G-actin-Alexa was determined as described under Materials and methods. G-actin-Alexa488 $\left(10 \mu \mathrm{g} . \mathrm{mL}^{-1}\right)$ was dissolved in $\mathrm{G}$ Buffer $(\boldsymbol{\Delta}), \tau=0.36 \mathrm{~ns} ; \mathrm{G}$ Buffer $+5 \%$ glycerol $(\mathbf{\square}), \tau=0.54$, ns; G Buffer $+25 \%$ glycerol $(\boldsymbol{O}), \tau=1.14 \mathrm{~ns} ; \mathrm{G}$ Buffer $+50 \%$ glycerol $(+), \tau=2.38$ ns.

kinetics of the static fluorescence anisotropy signal upon actin polymerization in cytosol of NIH-3T3 fibroblasts. The typical curve obtained is shown in Fig. 2a and fits to a single exponential which is consistent with pseudofirst-order kinetics. These kinetics are expected from the measurement of an elongation process, the concentration of actin-growing filaments remaining constant during the reaction. Fluorescence microscopy imaging confirms the formation of actin filaments under the assay conditions used. The actin filaments which formed were stained with phalloidin-Alexa488 that binds specifically and with a high affinity to F- but not to G-actin [20]. After 10 min at room temperature under polymerization conditions, we observed long and nonbranched filaments arranged in a parallel manner (Fig. 2b(ii)). Moreover, no actin filaments were observed in the absence of polymerization buffer in the reaction mixture (Fig. $2 b(i)$ ), the observed very small filaments being induced only by the propolymerizing effect of phalloidin.

Steady state fluorescence anisotropy experiments were performed in the presence of various protein concentrations of NIH 3T3 cytosolic fraction ranging from $25 \mu \mathrm{g} \cdot \mathrm{mL}^{-1}$ to $0.5 \mathrm{mg} \cdot \mathrm{mL}^{-1}$ (final protein concentration in reaction mixtures). Increasing the amount of proteins increased the steady state value and $k$ values up to 0.2 and $0.3 \mathrm{mg} \cdot \mathrm{mL}^{-1}$, respectively. Above these values, we observed a stabilization of $\Delta \mathrm{AU}$ and $k$ values (Table 2).

The plateaus of steady state values at concentrations up to $0.2 \mathrm{mg} \cdot \mathrm{mL}^{-1}$ suggest that, under these conditions and at the steady state, most of the actin-Alexa488 is incorporated in the actin filaments, indicating in turn that the polymerization process is highly favored. The plateau observed with the rate constant values of proteins up to $0.5 \mathrm{mg} \cdot \mathrm{mL}^{-1}$ suggests that, at high actin concentration, a rate-limiting factor controls the elongation process. For concentrations inferior to this saturating limit, we can evaluate a secondorder kinetics constant of approximately $0.36 \mathrm{~s}^{-1} \cdot \mathrm{mg}^{-1} \cdot \mathrm{mL}$ (Table 2b).

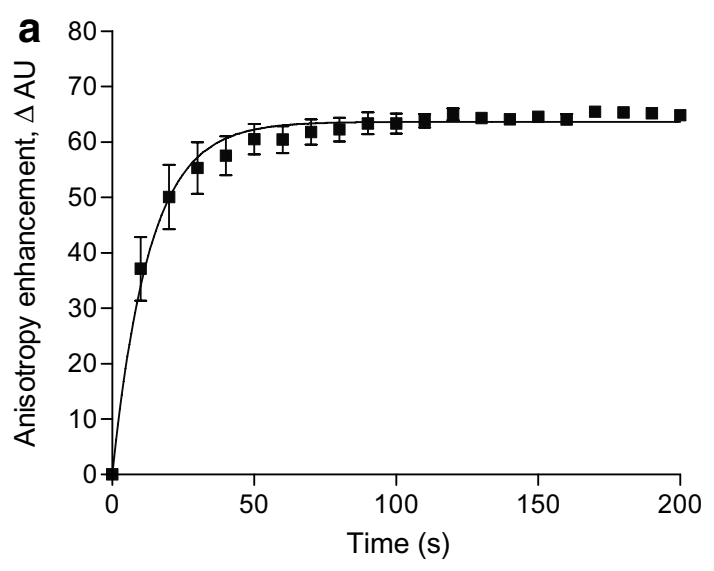

b (i) b (ii)
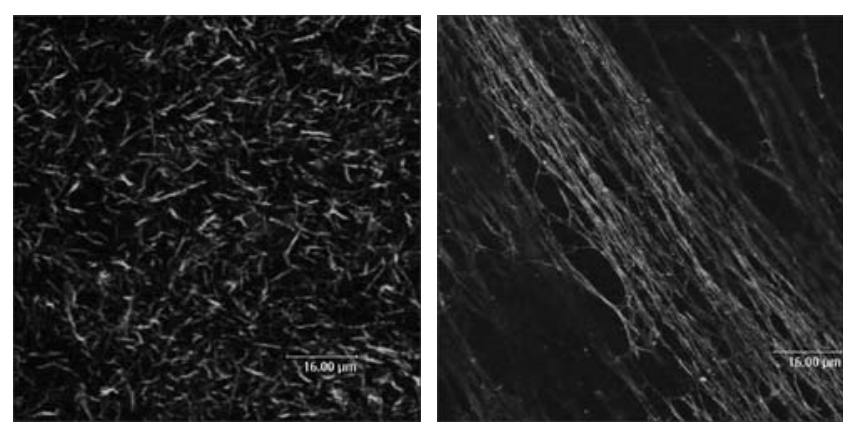

Fig. 2. (a) Fluorescence anisotropy enhancement in NIH 3 T3 cell extract. Polymerization buffer and cellular extract were added at time zero and anisotropy enhancement was followed at $22^{\circ} \mathrm{C}$ by actin-Alexa. Measurements were made every $10 \mathrm{~s}$. Final protein concentration in reaction mixture was $0.2 \mathrm{mg} \cdot \mathrm{mL}^{-1}$. The curve was fitted according to the equation $Y=Y_{\max }[1-\exp (-k \cdot x)]$. Data represent mean \pm standard deviation; $n=4$. (b) Confocal microscopy of actin filaments. Purified $\mathrm{G}$ actin $\left(0.2 \mathrm{mg} \cdot \mathrm{mL}^{-1}\right)$ was allowed to polymerize for $15 \mathrm{~min}$ at $37^{\circ} \mathrm{C}$, according to standard procedure. Phalloidin-Alexa488 was added at $0.15 \mu \mathrm{M}$ final concentration and allowed to bind to F-actin for $20 \mathrm{~min}$ at $37^{\circ} \mathrm{C}$.

Effect of divalent cations depletion on actin dynamics in NIH $3 T 3$ cytosolic fraction

The actin polymerization is well known to be highly dependent on the presence of divalent cations such as magnesium and calcium ones [21-23]. In the standard assay, calcium and magnesium ions were provided by the polymerization buffer and were present in cytosolic fractions of the cells. In a test assay, the decrease in the concentration of these cations should significantly impair the actin polymerization process. As shown in Fig. 3, polymerization buffer without magnesium ions results in slight decreases in the F-actin steady state value and in the rate constant. Polymerization buffer without calcium ions induced stronger effects on both steady state and rate constant: both steady state value and $k$ were decreased, respectively, to $40 \mathrm{AU}$ and $0.035 \mathrm{~s}^{-1}$.

We have further investigated the requirement of divalent cations for the F-actin elongation process by measuring the fluorescence anisotropy kinetics in the 
Table 2

(a) Effect of protein concentration on anisotropy enhancement in NIH 3T3 cell extract

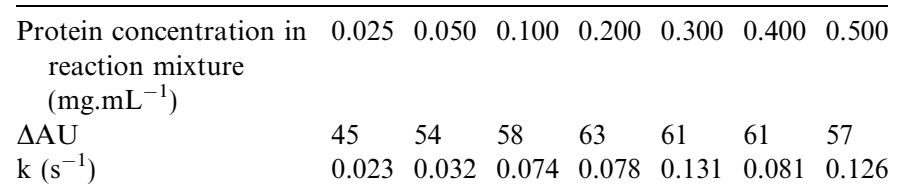

(b)

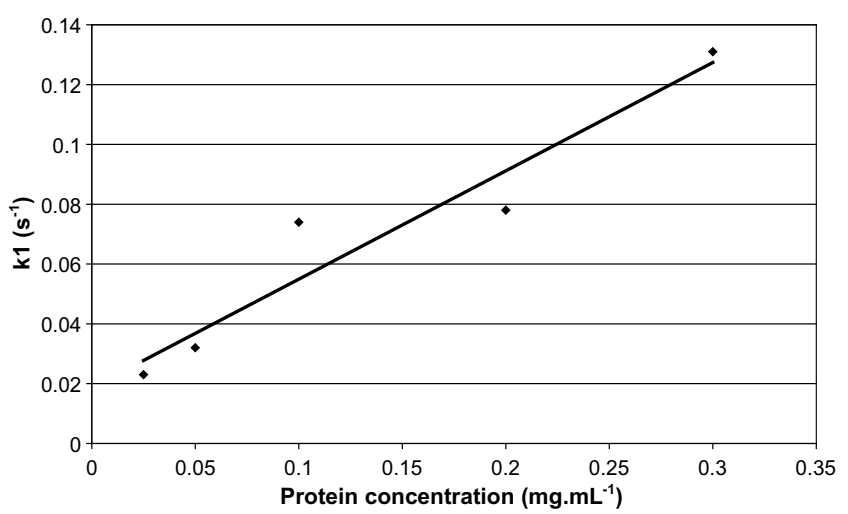

Anisotropy enhancement was followed at $22{ }^{\circ} \mathrm{C}$ for $200 \mathrm{~s}$, which is the time required to reach equilibrium, after addition of polymerization buffer and cellular extract. Data are expressed as mean of $\Delta \mathrm{AU}$ and constant $k$ calculated from at least three sets of data. The $\Delta \mathrm{AU}$, or steady state anisotropy value, corresponds to the equilibrium value and $k$ to the global rate of anisotropy enhancement. Standard deviation was inferior to 3\%. (b) Estimation of the second-order rate constant. $R^{2}=0.92$.

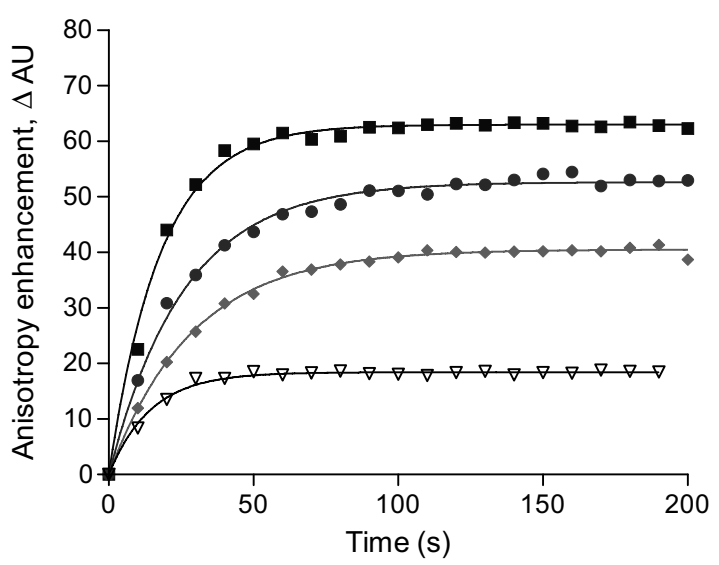

Fig. 3. Effects of depletion in magnesium and calcium cations on anisotropy enhancement in NIH 3T3 cell extract. The effect of depletion in $\mathrm{MgCl}_{2}(\bullet)$ and $\mathrm{CaCl}_{2}(\diamond)$ was first analyzed individually. For $\mathrm{Mg}^{2+}$ depletion, the sonication buffer and the polymerization buffer were prepared without $\mathrm{MgCl}_{2}$. To test the effects of depletion in calcium cations, no $\mathrm{CaCl}_{2}$ was added to $\mathrm{G}$ buffer. The effect of depletion of both of these compounds was also studied $(\nabla)$. Anisotropy enhancement curve with complete buffer is also shown for control (ם). Data represent mean \pm standard deviation; $n=4$.

presence of increasing concentration of the chelating agent EDTA. Fig. 4 shows that $1 \mathrm{mM}$ EDTA has only a slight effect on anisotropy kinetics and that, in contrast, addition of $5 \mathrm{mM}$ EDTA markedly decreases rate

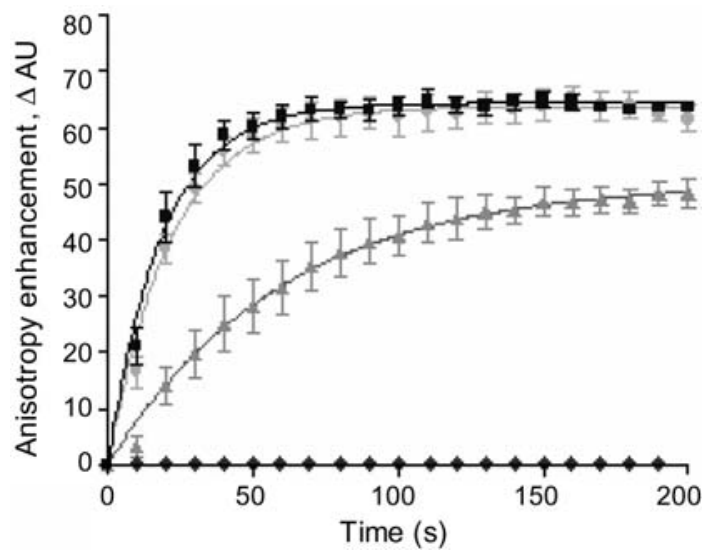

Fig. 4. Effect of divalent cations chelation by EDTA on anisotropy enhancement in NIH 3 T3 cell extracts. Experiments were performed using standard procedures. EDTA was added at time zero with polymerization buffer and NIH 3T3 cell extracts. Reaction mixtures contained EDTA at various concentrations symbolized as follows: $1 \mathrm{mM}$ EDTA $(\bullet), 5 \mathrm{mM}$ EDTA (४), 10 mM EDTA ( $)$, control buffer without EDTA (ם). Data represent mean \pm standard deviation; $n=3$.

constant and steady state values and addition of $10 \mathrm{mM}$ EDTA completely suppresses the anisotropy signal. F-actin microscopy imaging shows as expected that, in the presence of $10 \mathrm{mM}$ EDTA, F-actin fibers were no longer detected (data not shown). All these experiments suggest that the increase in anisotropy signal reflects the F-actin elongation process.

\section{Actin dynamics in malignant NIH 3T3-EF fibroblasts}

NIH 3T3-EF cells are immortal murine NIH 3 T3 fibroblasts which have been transfected by the oncoprotein EWS-Flil (EF) responsible for Ewing sarcoma [24]. NIH 3T3-EF, which display a malignant phenotype, are characterized by a major breakdown of the actin network organization, resulting in a polarized spindle cell shape, disappearance of stress fibers, loss of cell-cell adhesion, and increased motility. In NIH 3T3-EF, actin network alterations are mainly due to zyxin downregulation [25]. Actin dynamics of cytosolic fractions analyzed in NIH 3T3 and NIH 3T3-EF have been compared using fluorescence anisotropy measurement. Experimental data shown in Fig. 5 indicate that, in the NIH 3T3-EF cytosolic fraction, the F-actin elongation process is markedly impaired as indicated by a lower rate constant $\left(0.039 \mathrm{~s}^{-1}\right.$ instead of $0.078 \mathrm{~s}^{-1}$ with NIH 3T3) and a lower F-actin steady state value (42 AU instead of $63 \mathrm{AU}$ in NIH 3T3).

This experiment demonstrates that the assay allows discrimination of the actin dynamics status of cells. In the present case, the impairment of zyxin expression [25] - a protein directly involved in actin dynamics - is observed by the decrease of both $\mathrm{F}$-actin elongation rate constant and F-actin steady state values. These changes are consistent with the known role of zyxin which promotes actin polymerization and stabilizes F-actin. It is of interest to notice that the transfection of the zyxin 


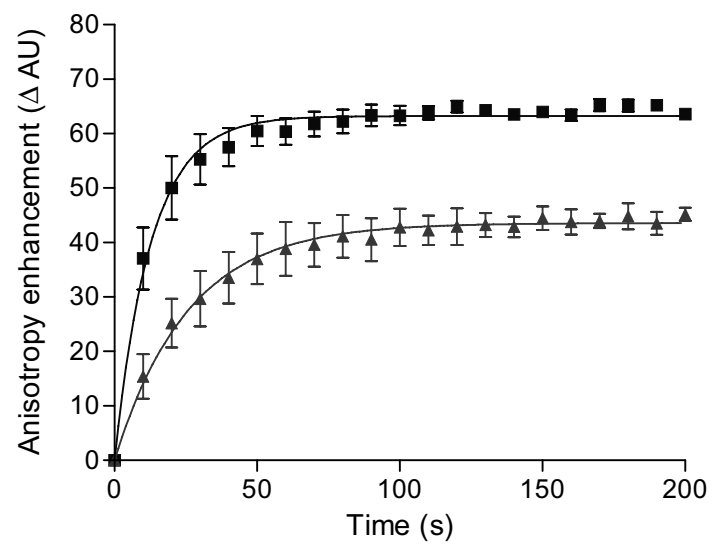

Fig. 5. F-actin elongation kinetics measured using cytosolic fractions of either NIH 3 T3 $(\boldsymbol{\square})$ or NIH 3T3-EF( $\boldsymbol{\Delta})$. Experiments were performed according to standard procedures. Polymerization buffer and cellular extract were added at time zero. Final protein concentration in reaction mixtures was $0.2 \mathrm{mg} \cdot \mathrm{mL}^{-1}$.

gene in NIH 3T3-EF results in the recovery of dynamics parameter values close to those measured in NIH 3T3 cells [25] (53 AU and $\left.0.064 \mathrm{~s}^{-1}\right)$. These results are gathered in Table 3.

\section{Effects of Jasplakinolide and Dolastatin 11 on actin dynamics measured using NIH 3T3-EF cytosolic fraction}

As stated above, NIH 3T3-EF cells display lower pseudo-first-order rate constants of actin elongation than native NIH 3T3 cells. They also have lower amounts of F-actin at steady state. We therefore assumed that cytosolic fractions issued from NIH 3T3-EF cells are suitable to screen molecules that may modulate actin dynamics, including those that could preferentially bind to actin filaments such as Jasplakinolide and Dolastatin 11. Previous studies have shown that these compounds enhance the actin polymerization rate and stabilize actin fibers, for both purified and intracellular actin [26,27].

Accordingly, when added to assay medium, both Jasplakinolide and Dolastatin 11 increase the F-actin elongation rate constant and the F-actin steady state value. Fig. 6

Table 3

Actin polymerization dynamic parameter of normal (NIH 3T3), transformed (NIH 3T3-EF) and transformed NIH 3T3-EF expressing zyxin (NIH 3T3-EF-Zyx) cells

\begin{tabular}{lll}
\hline Cells & $\Delta \mathrm{AU}$ & $\mathrm{k}\left(\mathrm{s}^{-1}\right)$ \\
\hline NIH 3T3 & 63 & 0.078 \\
NIH 3T3-EF & 42 & 0.039 \\
NIH 3T3-EF-Zyx & 53 & 0.064 \\
\hline
\end{tabular}

Anisotropy enhancement of cell extracts was followed at $22^{\circ} \mathrm{C}$ for $200 \mathrm{~s}$, which is the time required to reach equilibrium, after addition of polymerization buffer and cellular extract. Data are expressed as mean of $\Delta \mathrm{AU}$ and constant $k$ calculated from at least three sets of data. The $\Delta \mathrm{AU}$, or steady state anisotropy value, corresponds to the equilibrium value and $k$ to the global rate of anisotropy enhancement. Standard deviation was inferior to $3 \%$.

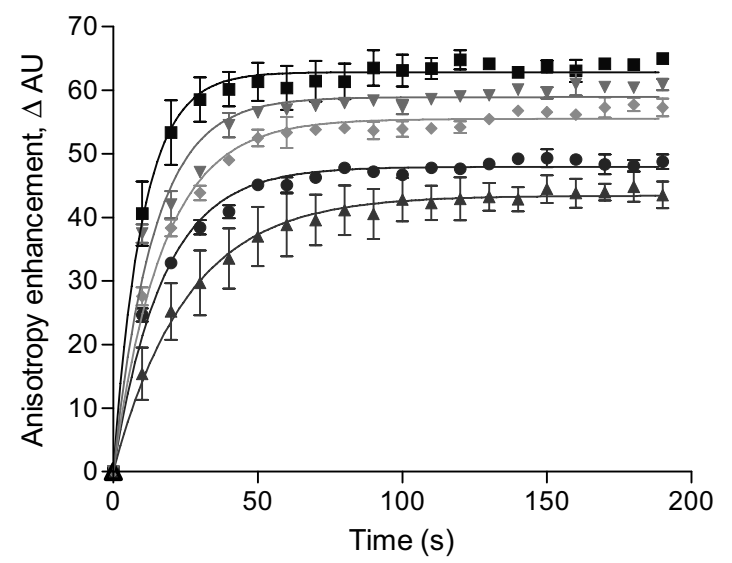

Fig. 6. Effect of Jasplakinolide on actin dynamics as measured using NIH 3T3-EF cytosolic fractions. Experiments were performed according to standard procedures. Various concentrations of Jasplakinolide were added at time zero with the polymerization buffer and NIH 3T3-EF cytosolic fraction. Reaction mixtures contained Jasplakinolide at concentrations symbolized as follows: NIH 3T3-EF $(\boldsymbol{\Delta})$; NIH 3T3-EF $+1 \mu \mathrm{M}$ Jasplak-

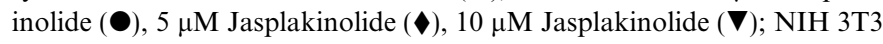
(ם). Data represent the mean of four experiments \pm SD.

shows typical kinetics observed following the addition of increasing concentrations of Jasplakinolide. In the presence of $10 \mu \mathrm{M}$ either Jasplakinolide or Dolastatin 11, the actin dynamics of NIH 3T3-EF cytosolic fractions is very similar to those observed using NIH 3T3 cytosolic fractions (Fig. 7). Thus, the enhancement of the anisotropy signal is in agreement with the expected effect of those two actin-polymerization-promoting agents.

\section{Discussion}

In the present study, we showed, by a variety of experiments, that the anisotropy signal enhancement-using G-actin-Alexa488 as marker-is correlated with the endogenous cell actin polymerization in NIH 3 T3 fibroblasts (it is noteworthy that fluorescence lifetime and quantum yield are not affected).

Anisotropy parameters provide information on the rotational relaxation of the chromophore and its local environment. Indeed, the rather fast anisotropy decay of actinAlexa488 (0.36 ns in G Buffer) indicates that we are measuring not the rotation of the whole labeled actin but rather the liberation of the Alexa488 chromophore around its linking moiety. The rotational correlation time $(\tau)$ of the actin-Alexa488 can be calculated with the Debye expression [28], $\tau=\frac{4 \pi R^{3} \eta}{3 k T}, R$ being the radius of a spherical object, $\eta$ the viscosity, $k$ the Boltzman constant, and $T$ the temperature. Considering that the globular labeled actin monomer is a spherical object of $5 \mathrm{~nm}$ in diameter [29], its correlation time is about $16 \mathrm{~ns}$ which is two orders of magnitude larger than the correlation time that we are measuring and studying in this test. After incorporation of the labeled monomer in the actin polymer, the rotational time increases. Again, it is not directly linked to the rotation of the actin polymer 

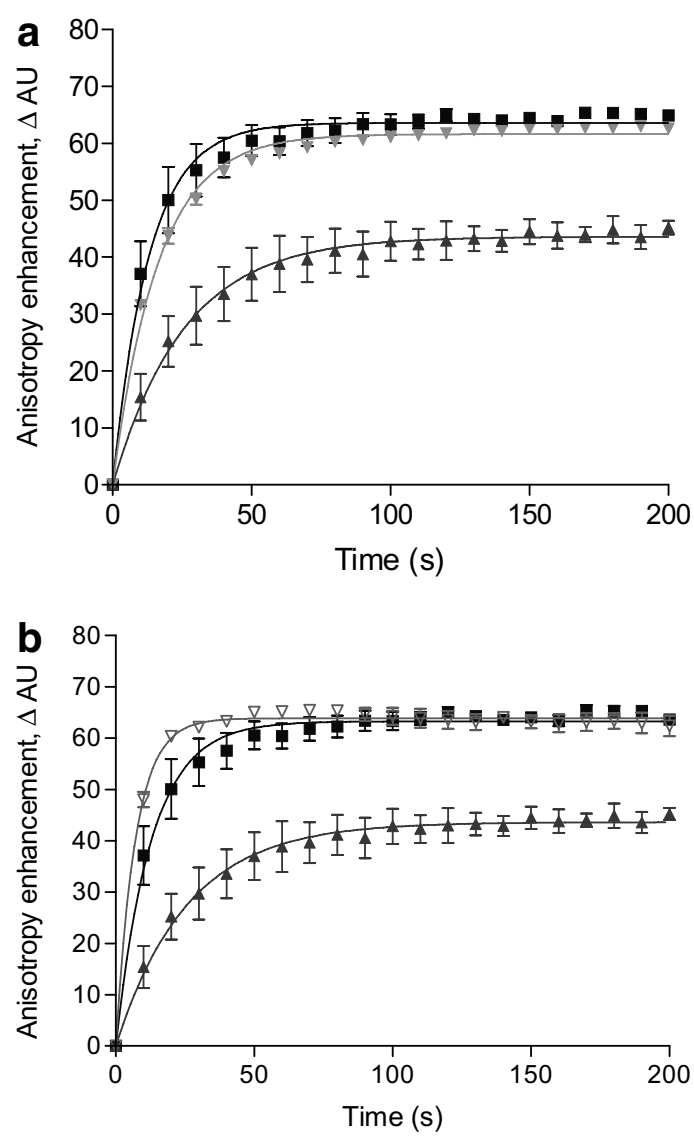

Fig. 7. Comparison of actin dynamics in NIH $3 \mathrm{~T} 3-\mathrm{EF}$ in the presence of Jasplakinolide (a) and Dolastatin 11 (b) with NIH 3T3 cell extracts. Experiments were performed according to standard procedures. Drugs (10 $\mu \mathrm{M}$ ) were added at time zero with the polymerization buffer and NIH 3T3 EF cytosolic fraction. (a) NIH 3T3-EF ( $\mathbf{\Delta}$ ), NIH 3T3-EF + $10 \mu \mathrm{M}$

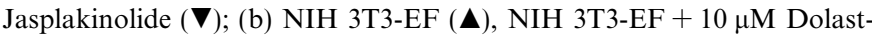
atin $11(\nabla)$. In a and b, control NIH 3T3 (ם). Data represent the mean of four experiments \pm SD.

which indeed is slowed but with a much longer characteristic time. Anisotropy is probing the local environment of Alexa488 which becomes more constrained in the polymer when subjected to limited motion for example when viscosity increases by addition of glycerol.

It should be noted that the time course of the polymerization process occurs according to pseudo-first-order kinetics which is in agreement with the occurrence of a simple elongation of a linear F-actin helix. Despite the complexity of the cellular extracts, i.e., the presence of actin dynamics regulatory proteins, we do not observe generation of new helixes or ramification of existing helixes which would lead to higher-order kinetics. This assay does not allow the investigation of the nucleation process. This is due to the fact that in cytosolic fractions, short F-actin helixes already preexist.

Furthermore, lowering the concentration of essential cofactors for actin polymerization (i.e., divalent cations) induced a decrease in anisotropy at equilibrium. The failure to obtain a total inhibition of anisotropy enhancement can be explained by the residual quantities of magnesium or calcium cations present in the cytosolic fractions. However, the total depletion of calcium and magnesium ions by addition of $10 \mathrm{mM}$ EDTA inhibits $100 \%$ anisotropy enhancement. We have also observed that, up to $0.2 \mathrm{mg} \cdot \mathrm{mL}^{-1}$, both the pseudo-first-order rate constant and the steady state anisotropy value were directly correlated to the protein concentrations. This is in agreement with the wellknown second-order kinetics which characterizes actin polymerization.

To investigate the potential applications of the proposed test, we attempted first to characterize the actin polymerization status of cytosolic fractions from malignant fibroblasts (NIH-3T3-EF) compared to nontransformed fibroblasts (NIH-3T3). Malignant cells have lower F-actin to G-actin ratio than normal cells [8,30-32]. The actin remodeling plays an important role in regulating tumor phenotypes. These changes are clearly associated with abnormal growth properties of tumor cells, alterations in cell shape, motility, and adhesion [33]. It was recently demonstrated that the actin network was strongly impaired in NIH 3T3-EF cells compared to NIH 3T3 cells. This is probably due to downregulation of zyxin - a protein that influences actin dynamics [34] in NIH 3T3-Ef cells.

In our experiments, tumor cells (transformed NIH 3T3EF) exhibit markedly lower pseudo-first-order rate constant of actin fiber elongation than untransformed NIH $3 \mathrm{~T} 3$ cells. They also display a lower steady state anisotropy value, corresponding to lower F-actin level at equilibrium. It should be noticed that actin fiber elongation parameters measured in cytosolic fraction issued from NIH 3T3-EF cells in which human zyxin has been transfected are closer to those observed in normal NIH 3T3. Interestingly, these transfected fibroblasts are no longer tumorigenic [25].

To ensure that the test could be used in screening drugs that modulate actin polymerization, we added well-known F-actin stabilizing compounds in the assay. Jasplakinolide and Dolastatin 11 are marine cyclic peptides known to bind actin filaments, to enhance the assembly of purified actin into F-actin $[26,27,35]$, and to stabilize F-actin by preventing actin depolymerization [27,36,37]. In this study, we have shown that these drugs modify the kinetics of actin polymerization in NIH 3T3-EF tumor cell extract, enhancing the quantity of F-actin to the value obtained with normal NIH 3T3 cell cytosolic fraction. These drugs enhanced also the global rate of actin polymerization $(k)$. This is in agreement with studies demonstrating that Jasplakinolide [38] and Dolastatin 11 [26] enhance the assembly of purified actin. Bai et al. [26] found also that Dolastatin 11 is more potent as on induce of actin assembly than is Jasplakinolide as an inducer of actin assembly.

These results indicate that the proposed test is suitable for evaluating the status of actin dynamics in cell extracts, taking also into consideration the possible impairment of proteins regulating actin dynamics. So far, contrary to measurements with purified actin, the conditions of this assay are the closest possible to the 
in vivo condition. It is also suitable for detecting compounds favoring actin polymerization through preferential binding to F-actin.

From a theoretical point of view, the test should also detect drugs modifying actin polymerization through interaction with actin dynamics regulatory proteins present in the cytosolic extracts. This is presently under investigation. Finally, the test can be easily adapted for high-throughput screening. It should be pointed out that the increase of the anisotropy signal following addition of exogenous molecules could be due to a direct binding of the tested drug to the actin-Alexa probe which artificially increases its anisotropy by locking the chromophore. In this case, the anisotropy signal occurs even in the presence of $10 \mathrm{mM}$ EDTA which totally prevents actin polymerization. This kind of control definitely excludes false positive results.

In conclusion, this analytical test appears to be accurate, reproducible, and easily automated for large-scale screening. Among other applications, it could also be used to identify new classes of drugs which may rescue actin dynamics breakdown present in tumor cells.

\section{Acknowledgments}

We thank Jacques Ghysdael (Laboratoire d'Oncologie Virale et Cellulaire, Centre National de la Recherche Scientifique, URA 1443, Institut Curie, Orsay, France) for the gift of the NIH 3T3-EF cell line and Robert B. Bates (Department of Chemistry, University of Arizona, Tucson, USA) for the gift of Dolastatin 11. We are grateful to Eric Deprez for helpful discussions on fluorescence anisotropy and to Adam Telerman for proofreading the manuscript.

\section{Appendix A. Supplementary data}

Supplementary data associated with this article can be found, in the online version, at doi:10.1016/j.ab.2007. 04.001 .

\section{References}

[1] T.D. Pollard, L. Blanchoin, R.D. Mullins, Molecular mechanisms controlling actin filament dynamics in nonmuscle cells, Annu. Rev. Biophys. Biomol. Struct. 29 (2000) 545-576.

[2] R.M. Bohmer, E. Scharf, R.K. Assoian, Cytoskeletal integrity is required throughout the mitogen stimulation phase of the cell cycle and mediates the anchorage-dependent expression of cyclin D1, Mol. Biol. Cell 7 (1996) 101-111.

[3] M. Iwig, E. Czeslick, A. Muller, M. Gruner, M. Spindler, D. Glaesser, Growth regulation by cell shape alteration and organization of the cytoskeleton, Eur. J. Cell Biol. 67 (1995) 145-157.

[4] O.C. Rodriguez, A.W. Schaefer, C.A. Mandato, P. Forscher, W.M. Bement, C.M. Waterman-Storer, Conserved microtubule-actin interactions in cell movement and morphogenesis, Nat. Cell Biol. 5 (2003) 599-609.

[5] G. Pawlak, D.M. Helfman, Cytoskeletal changes in cell transformation and tumorigenesis, Curr. Opin Genet Dev. 11 (2001) $41-47$.

[6] K.A. DeMali, K. Wennerberg, K. Burridge, Integrin signaling to the actin cytoskeleton, Curr. Opin. Cell Biol. 15 (2003) 572-582.
[7] J.Y. Rao, Y.S. Jin, Q. Zheng, J. Cheng, J. Tai, G.P. Hemstreet 3rd, Alterations of the actin polymerization status as an apoptotic morphological effector in HL-60 cells, J. Cell Biochem. 75 (1999) 686-697.

[8] J. Rao, N. Li, Microfilament actin remodeling as a potential target for cancer drug development, Curr. Cancer Drug Targets 4 (2004) 345354.

[9] C.D. Nobes, A. Hall, Rho, rac, and cdc42 GTPases regulate the assembly of multimolecular focal complexes associated with actin stress fibers, lamellipodia, and filopodia, Cell 81 (1995) 53-62.

[10] G. Zalcman, V. Closson, N. Honoré, B. Olofsson, A. Tavitian, Participation de la cascade des gènes Rho à la régulation du cytosquelette: rôle possible des mécanismes d'oncogenèse, Med. Sci. (Paris) 11 (1995) 1551-1556.

[11] T. Hunter, Oncoprotein networks, Cell 88 (1997) 333-346.

[12] A. Malliri, J.G. Collard, Role of Rho-family proteins in cell adhesion and cancer, Curr. Opin. Cell Biol. 15 (2003) 583-589.

[13] T. Kouyama, K. Mihashi, Fluorimetry study of N-(1-pyrenyl)iodoacetamide-labelled F-actin. Local structural change of actin protomer both on polymerization and on binding of heavy meromyosin, Eur. J. Biochem. 114 (1981) 33-38.

[14] J. Fradelizi, V. Noireaux, J. Plastino, B. Menichi, D. Louvard, C. Sykes, R.M. Golsteyn, E. Friederich, ActA and human zyxin harbour Arp2/3-independent actin-polymerization activity, Nat. Cell. Biol. 3 (2001) 699-707.

[15] Laurent, V., and Carlier, M.F., Use of platelet extracts for actinbased motility isteria monocytogenes, J.E. Celis, editor, San Diego, 1998.

[16] J.A. Cooper, T.D. Pollard, Methods to measure actin polymerization, Methods Enzymol. 85 (pt B) (1982) 182-210.

[17] F. Perrin, Polarisation de la lumière de fluorescence. Vie moyenne des molécules à l'état excité, J. Phys. Radium Ser. 6 (1926) 390-401.

[18] F. Perrin, La fluorescence des solutions. Induction moléculaire. Polarisation et durée d'émission. Photochimie, Ann. Phys. 10 (1929) 169-275.

[19] J.E. Bear, T.M. Svitkina, M. Krause, D.A. Schafer, J.J. Loureiro, G.A. Strasser, I.V. Maly, O.Y. Chaga, J.A. Cooper, G.G. Borisy, F.B. Gertler, Antagonism between Ena/VASP proteins and actin filament capping regulates fibroblast motility, Cell 109 (2002) 509-521.

[20] J.A. Cooper, Effects of cytochalasin and phalloidin on actin, J. Cell Biol. 105 (1987) 1473-1478.

[21] C.G. dos Remedios, D. Chhabra, M. Kekic, I.V. Dedova, M. Tsubakihara, D.A. Berry, N.J. Nosworthy, Actin binding proteins: regulation of cytoskeletal microfilaments, Physiol. Rev. 83 (2003) 433-473.

[22] L.C. Gershman, L.A. Selden, H.J. Kinosian, J.E. Estes, Actin-bound nucleotide/divalent cation interactions, Adv. Exp. Med. Biol. 358 (1994) 35-49.

[23] R. Cooke, The bound nucleotide of actin, J. Supramol. Struct. 3 (1975) 146-153.

[24] O. Delattre, J. Zucman, B. Plougastel, C. Desmaze, T. Melot, M. Peter, H. Kovar, I. Joubert, P. de Jong, G. Rouleau, et al., Gene fusion with an ETS DNA-binding domain caused by chromosome translocation in human tumours, Nature 359 (1992) 162-165.

[25] V. Amsellem, M.H. Kryszke, M. Hervy, F. Subra, R. Athman, H Leh, C. Brachet-Ducos, C. Auclair, The actin cytoskeleton-associated protein zyxin acts as a tumor suppressor in Ewing tumor cells, Exp. Cell. Res. 304 (2005) 443-456.

[26] R. Bai, P. Verdier-Pinard, S. Gangwar, C.C. Stessman, K.J. McClure, E.A. Sausville, G.R. Pettit, R.B. Bates, E. Hamel, Dolastatin 11, a marine depsipeptide, arrests cells at cytokinesis and induces hyperpolymerization of purified actin, Mol. Pharmacol. 59 (2001) 462-469.

[27] M.R. Bubb, I. Spector, B.B. Beyer, K.M. Fosen, Effects of jasplakinolide on the kinetics of actin polymerization. An explanation for certain in vivo observations, J. Biol. Chem. 275 (2000) 5163-5170.

[28] P.W. Atkins, Physical Chemistry, Oxford University Press, Oxford, 1990. 
[29] A.I. Norman, R. Ivkov, J.G. Forbes, S.C. Greer, The polymerization of actin: structural changes from small-angle neutron scattering, J. Chem. Phys. 123 (2005) 154904.

[30] C. Stournaras, E. Stiakaki, S.B. Koukouritaki, P.A. Theodoropoulos, M. Kalmanti, Y. Fostinis, A. Gravanis, Altered actin polymerization dynamics in various malignant cell types: evidence for differential sensitivity to cytochalasin B, Biochem. Pharmacol. 52 (1996) 1339-1346.

[31] G.P. Hemstreet 3rd, J. Rao, R.E. Hurst, R.B. Bonner, P. Waliszewski, H.B. Grossman, M. Liebert, B.L. Bane, G-actin as a risk factor and modulatable endpoint for cancer chemoprevention trials, J. Cell Biochem. Suppl. 25 (1996) 197-204.

[32] J. Katsantonis, A. Tosca, S.B. Koukouritaki, P.A. Theodoropoulos, A. Gravanis, C. Stournaras, Differences in the G/total actin ratio and microfilament stability between normal and malignant human keratinocytes, Cell Biochem. Funct. 12 (1994) 267-274.

[33] K. Weber, E. Lazarides, R.D. Goldman, A. Vogel, R. Pollack, Localization and distribution of actin fibers in normal transformed and revertant cells, Cold Spring Harb. Symp. Quant. Biol. 39 (Pt 1) (1975) 363-369.

[34] S. Amsellem, F. Pflumio, D. Bardinet, B. Izac, P. Charneau, P.H. Romeo, A. Dubart-Kupperschmitt, S. Fichelson, Ex vivo expansion of human hematopoietic stem cells by direct delivery of the HOXB4 homeoprotein, Nat. Med. 9 (2003) 1423-1427.

[35] R. Bai, D.G. Covell, C. Liu, A.K. Ghosh, E. Hamel, (-)-Doliculide, a new macrocyclic depsipeptide enhancer of actin assembly, J. Biol. Chem. 277 (2002) 32165-32171.

[36] T. Oda, Z.D. Crane, C.W. Dicus, B.A. Sufi, R.B. Bates, Dolastatin 11 connects two long-pitch strands in F-actin to stabilize microfilaments, J. Mol. Biol. 328 (2003) 319-324.

[37] B. Visegrady, D. Lorinczy, G. Hild, B. Somogyi, M. Nyitrai, The effect of phalloidin and jasplakinolide on the flexibility and thermal stability of actin filaments, FEBS Lett. 565 (2004) 163-166.

[38] M.R. Bubb, A.M. Senderowicz, E.A. Sausville, K.L. Duncan, E.D. Korn, Jasplakinolide, a cytotoxic natural product, induces actin polymerization and competitively inhibits the binding of phalloidin to F-actin, J. Biol. Chem. 269 (1994) 14869-14871. 